\title{
Using macrophage activation to augment immunotherapy of established tumours
}

\author{
Z G Fridlender ${ }^{\star}, 1,2$, A Jassar ${ }^{2}$, I Mishalian ${ }^{1}$, L-CS Wang ${ }^{2}$, V Kapoor ${ }^{2}$, G Cheng ${ }^{2}$, J Sun ${ }^{2}$, S Singhal ${ }^{2}$, \\ L Levy ${ }^{1}$ and S M Albelda ${ }^{2}$ \\ ${ }^{1}$ Institute of Pulmonary Medicine, Hadassah-Hebrew University Medical Center, POB 12000, Jerusalem 91120, Israel and \\ ${ }^{2}$ Thoracic Oncology Research Laboratory, University of Pennsylvania, Philadelphia, PA 19104, USA
}

\begin{abstract}
Background: Successful immunotherapy will require alteration of the tumour microenvironment and/or decreased immune suppression. Tumour-associated macrophages (TAMs) are one major factor affecting tumour microenvironment. We hypothesised that altering TAM phenotype would augment the efficacy of immunotherapy.
\end{abstract}

\begin{abstract}
Methods: We and others have reported that 5,6-Dimethylxanthenone-4-acetic-acid (DMXAA, Vadimezan) has the ability to change TAM phenotypes, inducing a tumour microenvironment conducive to antitumour immune responses. We therefore combined DMXAA with active immunotherapies, and evaluated anti-tumour efficacy, immune cell phenotypes (flow cytometry), and tumour microenvironment (RT-PCR).
\end{abstract}

\begin{abstract}
Results: In several different murine models of immunotherapy for lung cancer, DMXAA-induced macrophage activation significantly augmented the therapeutic effects of immunotherapy. By increasing influx of neutrophils and anti-tumour (M1) macrophages to the tumour, DMXAA altered myeloid cell phenotypes, thus changing the intratumoural M2/non-M2 TAM immunoinhibitory ratio. It also altered the tumour microenvironment to be more pro-inflammatory. Modulating macrophages during immunotherapy resulted in increased numbers, activity, and antigen-specificity of intratumoural CD8 ${ }^{+} \mathrm{T}$ cells. Macrophage depletion reduced the effect of combining immunotherapy with macrophage activation, supporting the importance of TAMs in the combined effect.
\end{abstract}

Conclusion: Modulating intratumoural macrophages dramatically augmented the effect of immunotherapy. Our observations suggest that addition of agents that activate TAMs to immunotherapy should be considered in future trials.

Current immunotherapies are primarily aimed at initiating or boosting T-cell responses to tumours and their antigens. Recent success has been seen in clinical trials with vaccines (Kantoff et al, 2010), adoptive T-cell transfer (Porter et al, 2011), and T cellactivating antibodies (Hodi et al, 2010). However, it is now also being increasingly realized that an immunosuppressive environment exists within tumours, induced by both cancer and immune cells, that inhibits the effect of cytotoxic $\mathrm{T}$ lymphocytes (Finn, 2008). As the effectiveness of immunotherapy may be limited by systemic and local tumour-induced immunosuppression, it is becoming more widely accepted that successful treatments will require a second agent to alter the tumour microenvironment and/or decrease immune suppression (Pardoll and Drake, 2012).

One of the major immune cells affecting the tumour microenvironment are tumour-associated macrophages (TAMs) (Mantovani et al, 2011). In early tumours, TAMs appear to have an inflammatory, tumouricidal (M1 or 'classically activated') phenotype. These TAMs are phagocytic, present antigens well, produce Th1-type cytokines, and are cytotoxic (Biswas et al, 2008). They may also indirectly promote cytotoxicity by activating other cells of the immune system, such as NK cells and T cells (Gabrilovich et al, 2012). However, as the tumour becomes established, macrophages polarise towards an 'alternatively 
activated' or M2-like phenotype, differing from M1 TAMs in receptor expression, antigen-presenting ability, function (e.g., arginine metabolism) , and cytokine production. These M2-like TAMs are accepted to have pro-tumour, angiogenic, and immunoinhibitory effects (Sica et al, 2007; Gabrilovich et al, 2012). The TAM phenotype is thus an important factor in tumour immunology (Biswas et al, 2008) and could have a role in the success or failure of immunotherapy.

The idea of targeting TAM as an antitumour approach was proposed many decades ago using extracts from bacterial walls (Killion and Fidler, 1994). Some successes were achieved in animal models, but the clinical trials were disappointing. Since then, a variety of anti-TAM therapies have been proposed and tested in preclinical models, including TAM depletion, differentiation, reprogramming, and activation (Sica et al, 2007). These approaches seem to have some efficacy, but rarely induce cures. Our group has conducted studies of TAM activation using a compound called 5,6-Dimethylxanthenone-4-acetic acid (DMXAA, Vadimezan), which is a small flavanoid-like compound that was originally developed as a vascular-disrupting agent (Zwi et al, 1990). Although endothelial cells may be directly affected, we and others found that DMXAA has powerful effects on the tumour microenvironment in mouse tumour models (Ching et al, 1999; Jassar et al, 2005; Roberts et al, 2007; Wallace et al, 2007). We have shown that DMXAA administered as monotherapy was able to induce inflammatory cytokine and chemokine secretion from TAMs that then stimulated antitumour CD8 responses and led to partial antitumour responses (Jassar et al, 2005).

Given the importance of TAMs in creating an inhibitory tumour microenvironment and our observation that DMXAA could change TAMs in mice towards a less immunosuppressive phenotype, we used this compound to test the hypothesis that combining macrophage activation with immunotherapy would augment efficacy. We thus evaluated the effect of DMXAA alone and in combination with immunotherapy in several murine cancer models. Our results showed that combination therapy resulted in increased antitumour effects. This appeared to be because of changes in the tumour microenvironment that resulted in increased CD8 T-cell migration and activation. This study supports the use of macrophage activation in combination with immunotherapy.

\section{MATERIALS AND METHODS}

Animals. Female C57BL/6 and BALB/C mice (6-8 weeks old, 20 $25 \mathrm{~g}$ ) were purchased from Charles River Laboratories (Wilmington, MA, USA). Protocols were approved by the Animal Use Committees of the University of Pennsylvania and of the Hebrew University in compliance with the Guide for the Care and Use of Laboratory Animals.

Cell lines. The TC1 cells were derived from mouse lung epithelial cells of a C57B6 mouse, immortalised with HPV-16 E6 and E7, and transformed with the c-Ha-ras oncogene (Lin et al, 1996). The murine bronchoalveolar carcinoma cell line L1C2 and the LLC (Lewis lung cell carcinoma) cells were obtained from the American Type Culture Collection (Rockville, MD, USA). Cell lines were regularly tested and maintained negative for mycoplasma spp.

5,6-Dimethylxanthenone-4 acetic-acid. 5,6-Dimethylxanthenone-4 acetic-acid (Vadimezan) was purchased from Sigma (St Louis, MO, USA). It was dissolved in sterile, distilled, and deionized water, and administered once by intraperitoneal (i.p.) injections at a dose of $18 \mathrm{mg} \mathrm{kg}^{-1}$ in $200 \mu \mathrm{l}$ water.

Immunotherapy models. We used several different immunotherapy models:
1. An E1/E3-deleted type 5 adenovirus expressing the HPV-E7 protein under control of a cytomegalovirus promoter as previously described (Ad.E7) (Haas et al, 2006). Animals bearing TC1 tumours were vaccinated subcutaneously (s.q.), contralateral to the tumour with $1 \times 10^{9}$ plaque-forming units (PFUs) of Ad.E7 vector. At 7 days after the initial vaccination, mice received a booster vaccine of $1 \times 10^{9}$ PFUs of Ad.E7.

2. A modified, live attenuated Listeria monocytogenes vector expressing the HPV-E7 protein (Lm.E7) was kindly provided by Dr Yvonne Paterson (Peng et al, 2004). Animals bearing TC1 tumours were vaccinated i.p. with 0.1 LD50 of Lm.E7 ( $10^{6}$ colonyforming units (CFUs)) of Lm.E7 vector. At 10 days after the initial vaccination, mice received a booster vaccine at the same dose.

3. Adenovirus expressing murine interferon- $\beta$ (Ad.IFN $\beta$ ) was constructed as previously described (Wilderman et al, 2005). Animals bearing LLC or L1C2 tumours were vaccinated subcutaneously (s.q.), contra-lateral to the tumour with $1 \times 1^{09}$ PFUs of Ad.IFN $\beta$ vector. With the TC1 cell line we also used a construct of adenovirus expressing murine interferon- $\gamma($ Ad.IFN $\gamma)$.

Animal flank tumour models. Mice were injected on the right flank with $1 \times 10^{6} \mathrm{TC1}$, LLC, or L1C2 tumour cells in the appropriate mouse strain. The flank tumours were allowed to reach an average size of $200-250 \mathrm{~mm}^{3}(\sim 12-15$ days). Mice were treated in one of the four groups: (1) control untreated, (2) DMXAA, (3) immunotherapy alone, or (4) a combination of immunotherapy and DMXAA. In some of the experiments, the control and DMXAA groups (groups 1 and 2) received an adenoviral vector encoding $\beta$-galactosidase (Ad.LacZ) (Wilderman et al, 2005) as control for the adenoviral constructs. All experiments had at least five mice per group and were repeated at least once. When needed for analysis (i.e., for FACS, RNA, cell subset isolation, and so on), flank tumours were harvested from the mice, and digested with $2 \mathrm{mg} \mathrm{ml}^{-1}$ DNase I (Sigma) and $4 \mathrm{mg} \mathrm{ml}^{-1}$ collagenase type IV (Sigma) at $37^{\circ} \mathrm{C}$ for $1 \mathrm{~h}$. This was done 3 days following the administration of DMXAA.

Flow cytometric analysis of tumours and spleens. Splenocytes, lymph nodes, and tumour cells were studied by FACS analysis as previously described (Haas et al, 2006). All fluorescently labelled antibodies used were purchased from BD Biosciences (San Jose, CA, USA) except for: CD206-PE, obtained from Serotec (Oxford, $\mathrm{UK})$; 4-1BB (CD137)-PE, obtained from Abcam (Cambridge, UK); and GR-1-FITC, obtained from eBioscience (San Diego, CA, USA). Flow cytometry was performed using a Becton Dickinson FACS Calibur flow cytometer (San Jose, CA, USA). Data analysis was done using FlowJo software (Ashland, OR, USA). The allophycocyanin-labelled $\mathrm{H}-2 \mathrm{D}^{\mathrm{b}}$ tetramer loaded with E7 peptide (RAHYNIVTF) was obtained from the National Institute of Allergy and Infectious Diseases tetramer core (Atlanta, GA, USA).

RNA isolation and real-time, reverse transcription-PCR. Tumours from mice treated with one of the four treatments detailed above were removed 2 days after the Ad.E7 boost vaccine, flash frozen, and the RNA from each tumour isolated. For each treatment condition, a pool of RNA was created by adding the same amount of RNA from each of the tumours within the group. Complementary DNA was made from each pool, RNA levels were normalised to $\beta$-actin levels, and quantification of tumour mRNA levels was performed as previously described (Fridlender et al, 2010). Relative levels of expression of each of the selected genes (fold change versus control) were determined. Each sample was run in quadruplicate and the experiment was repeated at least once. Primer sequences will be given upon request.

Macrophage depletion experiments. For the evaluation of the effect of macrophage depletion, we used Clodronate and control 
PBS liposomes purchased from Clodronate Liposomes Organisation (http://www.clodronateliposomes.org, Vrije Universiteit, The Netherlands). Liposomes were prepared at the concentration of $1 \mathrm{mg} \mathrm{ml}^{-1}$ as previously described (van Rooijen and van KesterenHendrikx, 2003). Systemic and local macrophage depletion was achieved by injection of Clodronate liposomes concomitantly intraperitoneally $(200 \mu \mathrm{l})$ and intratumourally $(100 \mu \mathrm{l})$. The percentage of macrophages in the spleen following use of liposomes was reduced by $\sim 90 \%$, and in the tumours by $50-60 \%$.

The $\mathrm{C} 57 \mathrm{Bl} / 6$ mice were injected on the right flank with $1-2 \times 10^{6}$ TC1 tumour cells. The flank tumours were allowed to reach an average size of $200-250 \mathrm{~mm}^{3}$ ( $\sim 10$ days). Mice were treated in one of the four groups: (1) control untreated, (2) Clodronate liposomes, (3) DMXAA + immunotherapy (Ad.E7) + PBS Liposomes, or (4) DMXAA + Ad.E7 + Clodronate Liposomes, and tumour growth was followed. Clodronate liposomes were injected 1 day after the first Ad.E7 vaccination and twice a week thereafter.

Statistical analyses. For the RT-PCR, FACS studies, and flank tumour studies comparing differences between two groups, we used unpaired Student's $t$-tests. For FACS and flank tumour studies comparing more than two groups, we used ANOVA with appropriate post hoc testing. Differences were considered significant when $P<0.05$. Data are presented as mean \pm s.e.m.

\section{RESULTS}

DMXXA significantly augments the effect of immunotherapy. We have previously shown that DMXAA induces a two-stage antitumour immune response in murine models of mesothelioma and lung cancer: an early, innate immune phase involving TAM activation, and a second, acquired immune phase involving $\mathrm{CD} 8^{+}$ $\mathrm{T}$ cells (Jassar et al, 2005). We have also shown that DMXAA directly activates dendritic cells enhancing antitumour-acquired immunity (Wallace et al, 2007). Given these activities, we tested the hypothesis that adding DMXAA to different models of lung cancer immunotherapy would enhance efficacy.

Figure 1 shows data evaluating the effect of combining DMXAA with two different vaccines directed against the human papilloma virus E7 antigen (HPV-E7) that is expressed in the TC1 murine lung cancer cell line. In both cases, mice with relatively large established tumours were treated with either: (1) saline control, (2) DMXAA alone, (3) two doses of an adenovirus expressing HPV-E7 (Ad.E7) (Figure 1A) or a modified listeria vector expressing HPVE7 (Lm-E7) (Figure 1B), or (4) a combination of vaccine and DMXAA. The DMXAA was delivered close to the time of the second vaccine dose.

In the Ad.E7 studies (Figure 1A), both the vaccine and DMXAA had significant $(P<0.05)$ but relatively modest effects on tumour growth. In contrast, when given in combination, there was clear tumour regression with a number of cures $(30-40 \%$ of animals in three independent experiments). These cured mice were followed for up to 50 days, with no recurrence. Furthermore, they were re-challenged with a second injection of TC-1 tumour cells that were rejected, with no tumour growth.

In the Listeria E7 studies (Figure 1B), DMXAA was not added until the tumours were very large $\left(>1000 \mathrm{~mm}^{3}\right)$. In this case, the vaccine had only a small temporary effect $(P=0.07)$ and there was no effect seen after DMXAA. This is consistent with our previous studies However, despite the presence of very large tumours, the combination therapy was significantly better than any of the individual treatments and actually induced tumour regressions ( $P<0.05$ compared with each of the other groups).

We also combined DMXAA with another type of immunogene therapy; intratumoural injection with an adenovirus expressing mouse interferon- $\beta$ (Ad.IFN- $\beta$ ). This vector, expressing the human form of interferon- $\beta$, has been tested in clinical trials (Sterman et al, 2010). In this model, we again saw the expected effects of Ad.IFN $\beta$ alone or DMXAA alone, but found augmented significant effects of the combination treatment in all three NSCLC cell lines tested, TC1, LLC, and L1C2 (Figure 1C-E). The TC1 was also combined with an injection with an adenovirus expressing mouse interferon- $\gamma$ (Ad.IFN- $\gamma$ ), with similar results (Figure 1F).

We have previously shown that using a sham adenoviral virus (Ad.LacZ) instead of active immunotherapy has no effect on tumour growth compared with adenovirus therapies (e.g., Ad.E7) (Wilderman et al, 2005). We further evaluated the combination of DMXAA with Ad.LacZ in both TC1 and LLC, and found no additional effect compared with DMXAA alone (see also Supplementary Figure 2).

The data presented above suggest that macrophage activation at the time when immunotherapy-induced antitumour CD8 T cells are present can augment efficacy. Given the dramatic effects in the TC1 model and our ability to track antigen-specific T cells in this system, we used this model for mechanistic studies. We examined the effects on both the innate and acquired immune responses.

DMXAA treatment alters the myeloid cell phenotypes by increasing the influx of neutrophils and antitumour (M1) macrophages to the tumour, thus changing the intratumoural M2/non-M2 TAM immunoinhibitory ratio. Given previous studies that have shown that DMXAA induced the intratumoural influx of macrophages and neutrophils (Jassar et al, 2005; Wang et al, 2009), we next examined the phenotype of tumour-associated myeloid cells, including TAMs, tumour-associated neutrophils (TANs), and dendritic cells (DCs) in tumours treated with immunotherapy, and harvested 3 days after DMXAA. At this time the immediate effects of DMXAA would be resolved, but the tumours in each group were relatively similar in size, allowing the most useful comparisons.

As a first way of evaluating this issue, we took tumour extracts from this time point and performed RT-PCR with primers that identified myeloid cells (CD11b), neutrophils (Ly6G), and protein mRNAs associated with M1 macrophages (iNOS) or M2 macrophages (CD206 or the macrophage mannose receptor-2 (MMR2)) and compared untreated tumours, tumours treated with Ad.E7 alone, DMXAA alone, or the combination. As shown in Table 1, at this time point, we saw relatively few changes in the DMXAAtreated tumours. In mice treated only with Ad.E7, the message of CD8 was increased, and that of Ly6G decreased. However, when we compared combination treatment with Ad.E7, we noted significant increases in CD11b, Ly6G, and iNOS, with a significant decrease in the MMR, suggesting a change in the tumour microenvironment.

To more precisely evaluate specific cell types, tumours were digested and subjected to FACS. Figure 2A shows that DMXAA, Ad.E7, and combo therapy all mildly but significantly $(P<0.05)$ increased macrophages (defined as $\mathrm{CD} 11 \mathrm{~b}^{+} / \mathrm{CD} 11 \mathrm{c}^{-} / \mathrm{Ly} 6 \mathrm{G}^{-}$) and DCs (defined as CD $11 \mathrm{~b}^{+} / \mathrm{CD} 11 \mathrm{c}^{+} / \mathrm{Ly}_{6 \mathrm{G}}{ }^{-}$) to a similar same extent compared with control tumours, with cell percentages increasing by $\sim 30-70 \%$. In contrast, the increase in neutrophils $\left(\mathrm{CD}_{11 \mathrm{~b}}{ }^{+} / \mathrm{CD} 11 \mathrm{c}^{-} / \mathrm{Ly}_{6 \mathrm{G}}{ }^{+}\right)$was much more impressive in the combination group $(P<0.05)$ compared with control or either treatment alone.

We then evaluated for major changes in the phenotypes of

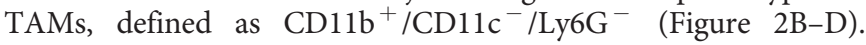
There were no significant differences in the percentage of alternatively activated, tumour-promoting, M2 macrophages (defined as $\mathrm{CD} 11 \mathrm{~b}^{+} / \mathrm{F} 4 / 80^{+} / \mathrm{CD} 206^{+}$) out of total tumour cells with either treatment alone or by combining DMXAA and the vaccine (Figure $2 \mathrm{~B}$ ). In contrast, in both combination models we evaluated, the TC1 cell line with Ad.E7 (left panel) and LLC cell 
A

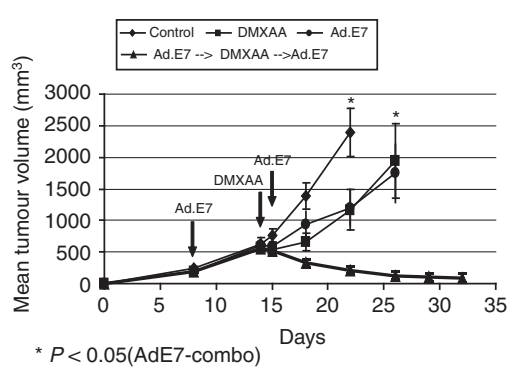

C

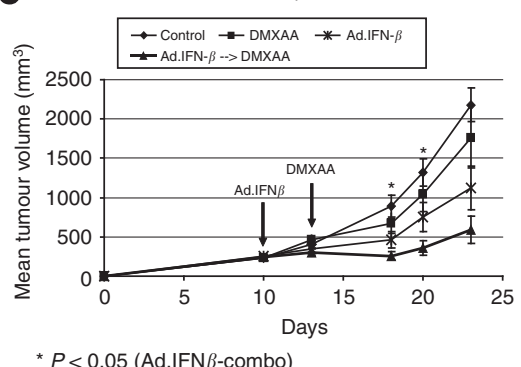

$\mathbf{E}$

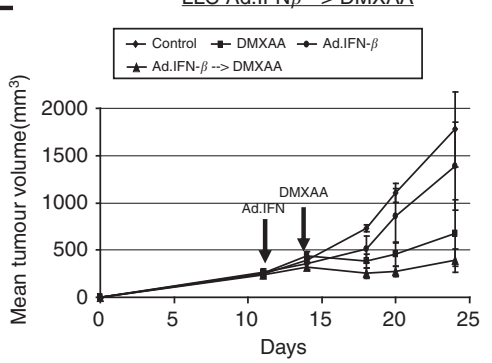

B

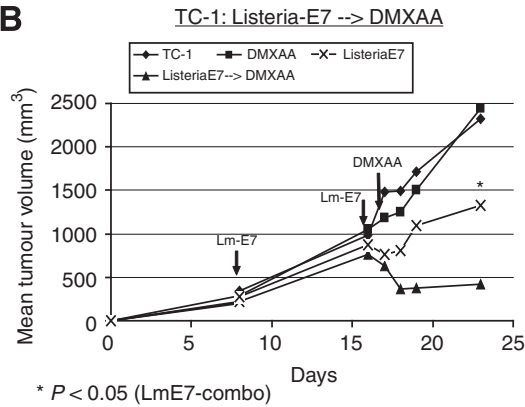

D

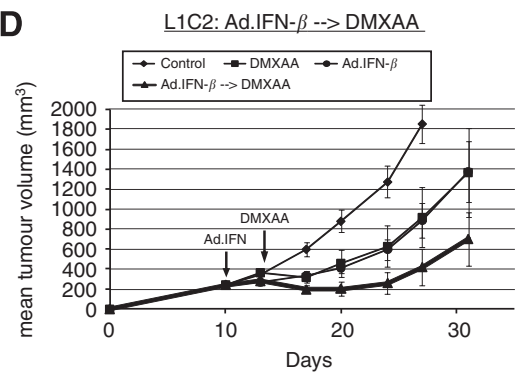

$\mathbf{F}$

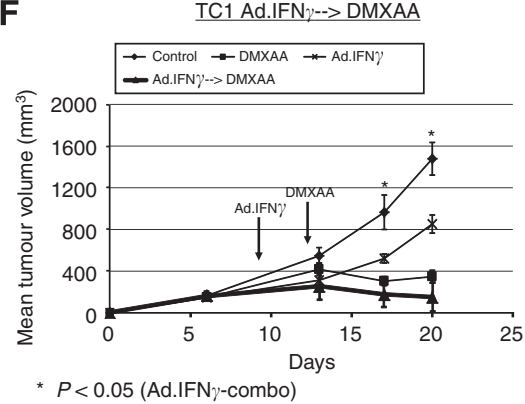

Figure 1. 5,6-Dimethylxanthenone-4-acetic-acid (DMXAA) significantly augments tumour immunotherapy. Mice bearing large flank tumours were treated in one of the four ways: (1) no treatment (control), (2) i.p. DMXAA (single dose), (3) immunotherapy, and (4) a combination of immunotherapy and DMXAA (Combo). In all models presented, combination therapies led to clear tumour regression compared with each treatment alone. The following combinations of immunotherapy and DMXAA in murine lung cancer cell lines are shown: (A) the TC1 cell line with adenovirus expressing HPV-E7 (Ad.E7). (B) The TC1 cell line with a modified listeria vector expressing HPV-E7 (Lm-E7). (C) The TC1 cell line with adenovirus expressing interferon- $\beta$ (Ad.IFN $\beta$ ). (D) The L1C2 cell line with adenovirus expressing interferon- $\beta$ (Ad.IFN $\beta$ ). (E) The LLC cell line with adenovirus expressing interferon- $\beta$ (Ad.IFN $\beta$ ). (F) The TC1 cell line with adenovirus expressing interferon- $\gamma($ Ad. IFN $\gamma)$. ${ }^{*} P<0.05$ in combination therapy versus immunotherapy alone.

line with Ad.IFN $\beta$ (right panel), DMXAA significantly increased the percentage of the classically activated, tumour-inhibitory ' $\mathrm{M} 1$ ' macrophages (defined as CD $11 \mathrm{~b}^{+} / \mathrm{F} 4-80^{+} / \mathrm{CD} 206^{-}$) by approximately two-fold compared with vaccine alone $(P<0.05)$. These data were consistent with our RT-PCR data showing increases in mRNA of iNOS and TNF $\alpha$, known to be M1 TAM markers (Table 1). We further evaluated using flow cytometry several known markers of M1/M2 macrophages (Sica et al, 2008). We found that adding DMXAA to immunotherapy increased the expression of two known markers of M1 macrophages, CCR-7 and CD127, and reduced the level of intracellular IL-10, a known M2 macrophage marker (Supplementary Figure 1). The percentage of the immature/undifferentiated ' $\mathrm{M} 0$ ' macrophages (defined as $\mathrm{CD}_{11 \mathrm{~b}^{+} / \mathrm{F} 4-80^{-} / \mathrm{Ly} 6 \mathrm{G}^{-}}$) was also significantly increased in the combination group (Figure 2B). Representative FACS traces of TAMs are shown in Figure 2C, showing the relative proportion of M2 and M1 within the macrophage population.

To quantify the impact of these changes in the phenotype of macrophages, we calculated an 'immunostimulation ratio', that is, the ratio of the non-M2 TAM (antitumour) cells to the M2 TAM (protumour) cells. In control tumours, this ratio is $\sim 1$, suggesting an immunoinhibitory environment. After treatment with either
DMXAA or Ad.E7, this ratio increases somewhat in both immunotherapy systems evaluated. However, following combined treatment, this ratio increased markedly in the TC-1-Ad.E7 model up to 19: 1 (Figure 2D, top panel, $P<0.05$ compared with all other treatments). In the LLC-Ad.IFN $\beta$ model, the ratio in the combination treatment was also significantly increased when compared with DMXAA alone (Figure 2D, bottom panel, $P<0.05)$. In summary, combination treatment markedly shifted the tumour-associated myeloid population towards a more antitumour phenotype.

DMXAA changes the tumour microenvironment to be more pro-inflammatory. Given our previous data showing that DMXAA alone altered the tumour microenvironment, we characterised the effect of DMXAA alone and in combination with Ad.E7 on the tumour microenvironment. We aimed to show how these changes in the phenotype of myeloid cells using DMXAA added to the changes in tumour inflammatory milieu previously noted with immunotherapy. We used real-time RT-PCR of tumour extracts harvested 3 days after DMXAA to profile a set of relevant cytokines, chemokines, and cell adhesion molecules (Table 1). As previously reported, DMXAA alone 
Table 1. Real-time RT-PCR level in whole tumours

\begin{tabular}{|l|c|c|c|c|c|}
\hline PCR & Control & DMXAA & AdE7 & $\begin{array}{c}\text { AdE7 }+ \\
\text { DMXAA }\end{array}$ & $\begin{array}{c}\text { P-value } \\
\text { (Ad.E7 versus } \\
\text { combination) }\end{array}$ \\
\hline TNF $\alpha$ & 1 & 1.6 & 1.2 & $\mathbf{3 . 9}$ & $<0.01$ \\
\hline $\begin{array}{l}\text { CCL5 } \\
\text { (RANTES) }\end{array}$ & 1 & 1.4 & 3 & $\mathbf{4 . 3}$ & 0.01 \\
\hline IFN $\gamma$ & 1 & 2.2 & 3.5 & 4.4 & 0.11 \\
\hline TGF $\beta$ & 1 & 0.9 & 1.9 & 1.5 & 0.08 \\
\hline ICAM-1 & 1 & 1 & 1 & 1.6 & 0.04 \\
\hline $\begin{array}{l}\text { CXCL-10 } \\
\text { (IP-10) }\end{array}$ & 1 & 1 & 2.8 & 2.8 & NS \\
\hline $\begin{array}{l}\text { CCL2 } \\
\text { (MCP-1) }\end{array}$ & 1 & 1 & 2.4 & 2.8 & NS \\
\hline VEGF & 1 & 1 & 0.9 & 1 & NS \\
\hline MMR & 1 & 0.8 & 0.7 & $\mathbf{0 . 4}$ & $<0.01$ \\
\hline iNOS & 1 & 1 & 0.6 & 1.6 & $<0.01$ \\
\hline CD8 & 1 & 1.8 & 4.7 & 12.9 & $<0.01$ \\
\hline CD11b & 1 & 0.9 & 1.2 & $\mathbf{3 . 1}$ & $<0.01$ \\
\hline Ly6G & 1 & 0.6 & 0.4 & 1.8 & $<0.01$ \\
\hline & & & & & \\
\hline
\end{tabular}

Abbreviations: $\mathrm{CCL} 2=$ chemokine ( $\mathrm{C}-\mathrm{C}$ motif) ligand 2: $\mathrm{CCL} 5=$ chemokine ( $\mathrm{C}-\mathrm{C}$ motif) ligand 5; CXCL-10 = chemokine (C-X-C motif) ligand 10; DMXAA = 5,6-Dimethylxanthenone-4-aceticacid; ICAM-1 = intercellular adhesion molecule 1; $\mathrm{NNOS}=$ inducible nitric oxide synthase; IFN $\gamma=$ interferon- $\gamma ;$ IP-10 $=$ interferon- $\gamma$-induced protein 10; MCP-1 = monocyte chemotactic protein-1; MMR = macrophage mannose receptor; NS = not significant; RANTES = regulated and normal T cell expressed and secreted; RT-PCR = reverse transcription-PCR; TGF $\beta=$ transforming growth factor- $\beta$; TNF $\alpha=$ tumor necrosis factor- $\alpha$; VEGF $=$ vascular endothelial growth factor. Mice ( $n=4-5$ for each group) bearing large (average size of $200-250 \mathrm{~mm}^{3}$ ) TC1 tumours were treated in one of the four ways: (1) control, no treatment (Control); (2) intraperitoneal (i.p.) DMXAA; (3) subcutaneous (s.q.) vaccine with Ad.E7, and a booster vaccine after a week (Ad.E7); and (4) a combination of Ad.E7 and DMXAA given 1 day before the second Ad.E7 injection (Combo). At 2 days after the second (booster) Ad.E7 vaccine, tumours were harvested, digested, and RNA was extracted. Equal amounts of RNA from each tumour in each group were pooled, complementary DNA (CDNA) generated, and subjected to real-time RT-PCR analysis. RNA was normalised using glyceraldehyde 3-phosphate dehydrogenase (GAPDH) levels. Each assay was run in at least quadruplicate. Fold change with each treatment compared with control is shown. Major changes between immunotherapy alone and the combination with DMXAA are in bold.

modestly increased the mRNA levels of TNF $\alpha$, CCL5, and IFN $\gamma$. The mRNA expression levels of these cytokines were also elevated by the vaccine alone, along with those of CXCL10, CCL2, TGF $\beta$. However, the expression levels of $\mathrm{TNF} \alpha$, IFN $\gamma$, and CCL5, were $\sim 1.5$ - to 2 -fold higher in the combination group compared with the Ad.E7 alone group $(P<0.05$ for each except for IFN $\gamma)$. In addition, ICAM-1 was significantly increased only in the combination therapy group $(P=0.04)$.

DMXAA in mice treated with immunotherapy increases the number, the activation state, and the antigen specificity of intratumoural $\mathrm{CD8}^{+} \mathrm{T}$ cells. As we have previously shown that DMXAA induces an influx of $\mathrm{CD} 8{ }^{+}$CTLs into the tumour (Jassar et al, 2005), we next evaluated the total numbers of $\mathrm{CD}^{+}$cells infiltrating the tumours in animals treated with DMXAA with and without immunotherapy. We again studied the tumours 2 or 3 days following the boost vaccination with Ad.E7, a time point at which there was no significant change in tumour size, making comparisons more equitable.

At this time point, in the TC1-Ad.E7 model, DMXAA as monotherapy increased the number of intratumoural $\mathrm{CD} 8^{+}$cells by approximately five-fold (Figure $3 \mathrm{~A}, P<0.05$ ). The Ad.E7 vaccine induced a significant influx of $\mathrm{CD}{ }^{+}$cells into the tumour as well, increasing the percentage of $\mathrm{CD}^{+}$cells by three-fold compared with control (Figure 3A, $P<0.05$ ). However, the combination of vaccine with DMXXA more than doubled the percentage of intratumoural $\mathrm{CD}^{+}$cells compared with vaccine alone, as seen by flow cytometry (Figure $3 \mathrm{~A}$ and representative FACS traces in Figure $3 \mathrm{C}, P<0.05)$. In the LLC-IFN $\beta$ model, the number of intratumoural $\mathrm{CD}^{+}$cells was not changed with either treatment alone. The combined treatment, however, approximately doubled their number compared with any of the treatments alone (Figure 3B, $P<0.05$ compared with all groups). These findings were corroborated by similar increases in the expression levels of CD8 mRNA in the treated tumours using real-time RT-PCR (Table 1).

To assess the effect of the combination therapy on $\mathrm{CD} 8{ }^{+} \mathrm{T}$-cell activation, we measured the expression of the surface activation markers 4-1BB (CD137) (Dawicki and Tania, 2004; Kim et al, 2008 ) and CD25 in CD8 ${ }^{+}$cells. The percentage of activated intratumoural $\mathrm{CD}^{+} \mathrm{T}$ cells, defined as $\mathrm{CD} 8^{+} / 4-1 \mathrm{BB}^{+}$(Figure $4 \mathrm{~A}$ ) or $\mathrm{CD}^{+} / \mathrm{CD}^{2} 5^{+}$(Figure $4 \mathrm{~B}$ ), generally followed the same pattern as the percentage of total intratumoural $\mathrm{CD}^{+}$cells in both models evaluated. $\mathrm{CD}^{+}$cell activation was increased in all treatment groups compared with control. The percentage of activated CD8 ${ }^{+}$ cells was increased in the combination treatment compared with Ad.E7 alone. However, this difference in the TC1-Ad.E7 model did not quite reach statistical significance $(P=0.06)$.

Finally, we studied the infiltration of antigen-specific CD8 ${ }^{+}$ T cells. The murine NSCLC line TC1, which expresses the HPV-E7 peptide, enabled us to directly evaluate the reactivity of $\mathrm{CD} 8^{+}$ $\mathrm{T}$ cells to a specific tumour antigen (HPV-E7) by flow cytometry using tetramers (Haas et al, 2006). Both immunotherapy and DMXAA alone increased the percentage of intratumoural E7-specific $\mathrm{CD}^{+}$cells by approximately two-fold as shown by tetramer staining (Figure 4C); however, this increase was not statistically significant. In contrast, combining DMXAA with Ad.E7 vaccine increased the percentage of tetramer-positive $\mathrm{CD} 8{ }^{+}$cells by four-fold compared with control $(P<0.01)$ and two-fold compared with vaccine alone $(P<0.05)$ and DMXAA alone $(P=0.057)$.

Depletion of macrophages reduces the effect of combining immunotherapy with DMXAA. In order to demonstrate the importance of macrophages in the additive effect of DMXAA and immunotherapy, we used Clodronate liposomes to deplete tumour macrophages, as previously described (van Rooijen and van Kesteren-Hendrikx, 2003). Mice with TC1 tumours were treated with the combination of Ad.E7 and DMXAA, either with or without treatment with Clodronate liposomes and tumour size compared (Figure 5). As can be seen in the two left columns of Figure 5, and consistent with previous work, treatment with Clodronate liposomes alone significantly reduced tumour size compared with control mice treated with unloaded liposomes $(P=0.05)$, demonstrating the known pro-tumour role of untreated TAMs (Mantovani et al, 2011). When mice were treated with the combination of immunotherapy and DMXAA, tumour size was markedly and significantly reduced, with 6 out of 8 cured at 1 week after the second injection of AdE7 (Figure 5, third column). Consistent with our phenotypic data, depletion of 'activated' TAMs with clodronate liposome treatment given concomitantly with Ad.E7 plus DMXAA inhibited therapeutic efficacy, resulting in significantly larger tumours and no cures (Figure 5, right column).

Combining DMXAA with immunotherapy does not change systemic (splenic) $\mathrm{CD8}^{+} \mathrm{T}$ cells. We next studied the systemic effects of combination therapy by evaluating splenocytes. We found no significant changes in the percentage of myeloid-derived suppressor cells $\left(\mathrm{CD} 11 \mathrm{~b}^{+} / \mathrm{GR} 1^{+}\right), \mathrm{B}$ cells, CD8 ${ }^{+}$cells, CD4/ $\mathrm{CD}^{+} 5^{+}$(T regulatory) cells, or CD4/CD25 cells (data not shown).

In the evaluation of $\mathrm{CD} 8^{+} \mathrm{T}$ cells, DMXAA, by itself, did not change the percentage of HPV-E7-specific $\mathrm{CD} 8^{+}$cells in the spleen compared with control tumour-bearing mice. As expected, Ad.E7 immunotherapy increased the percentage of splenic E7-specific $\mathrm{CD}^{+}$cells by almost four-fold. Addition of 

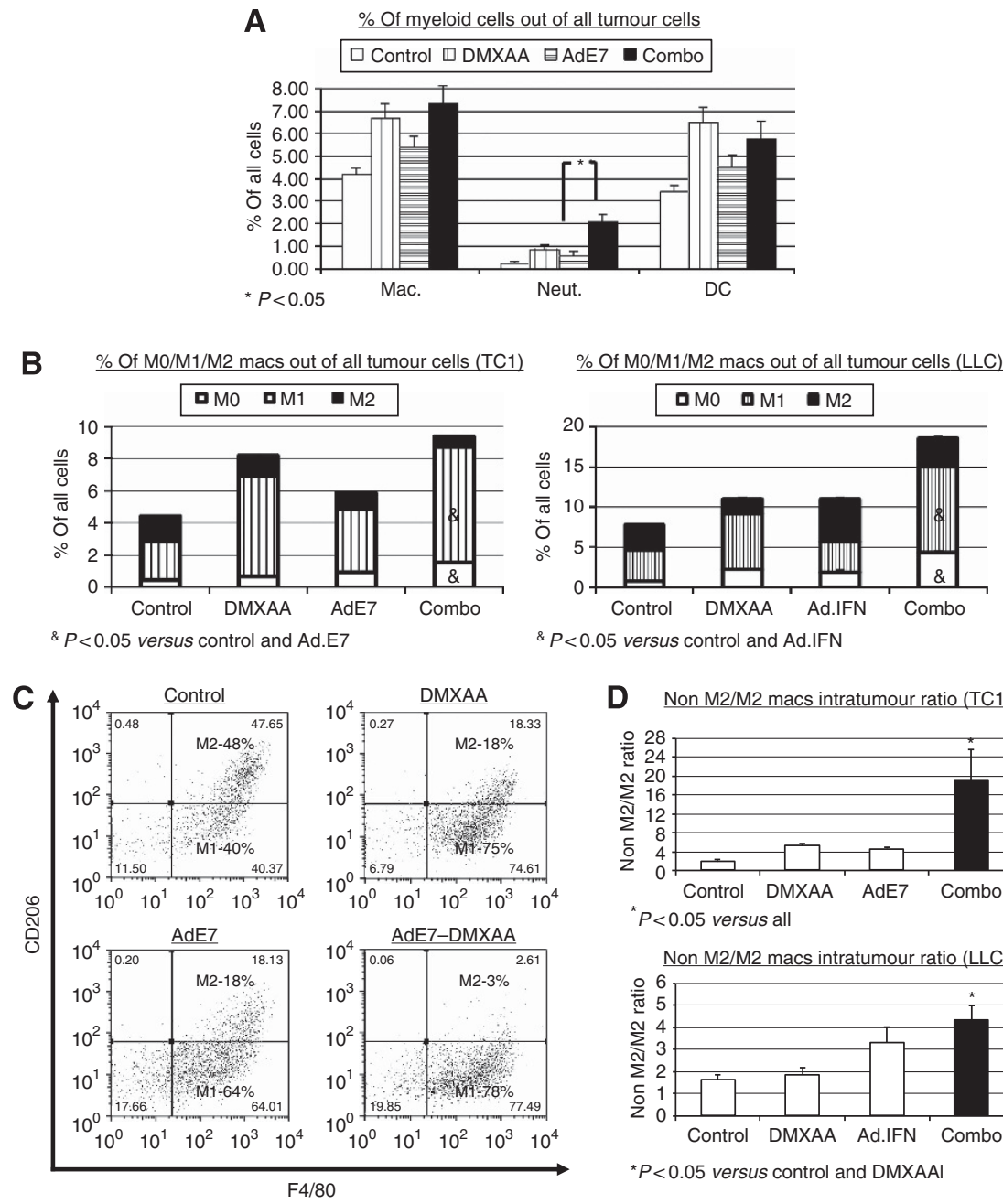

D Non M2/M2 macs intratumour ratio (TC1)
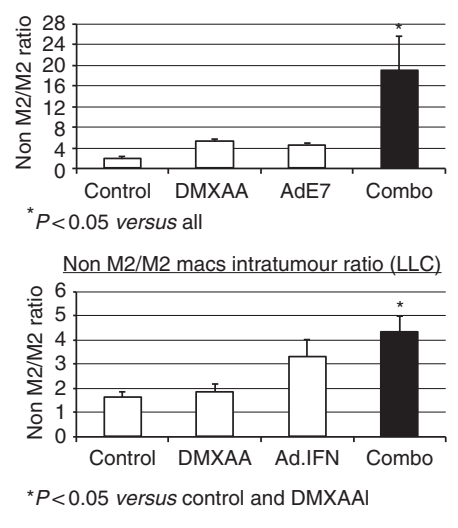

Figure 2. 5,6-Dimethylxanthenone-4-acetic-acid (DMXAA) alters the myeloid cell phenotypes induced by immunotherapy. Mice ( $n=4-6$ for each group) bearing large TC-1 or LLC tumours were treated in one of the four ways: (1) no treatment (Control), (2) i.p. DMXAA, (3) s.q. vaccine with Ad.E7 in the TC1 cell line (Ad.E7) or Ad.IFN $\beta$ in the LLC cell line, and (4) combination of Ad.E7/Ad.IFN $\beta$ and DMXAA. At 3 days after the injection of DMXAA, tumours were harvested. (A) The percentage of different myeloid cells out of all tumour cells in the TC1 cell line model is summarised. Combo therapy, DMXAA, and Ad.E7 all significantly $(P<0.05)$ increased macrophages (defined as CD11 $\mathrm{b}^{+} / \mathrm{CD} 11 \mathrm{c}^{-} / \mathrm{Ly}_{6 \mathrm{G}}{ }^{-}$) and DCs (defined as CD11 $\mathrm{b}^{+} / \mathrm{CD} 11 \mathrm{c}^{+} /$ Ly6G $^{-}$) compared with control tumours to a similar extent. Neutrophils (defined as CD11 $\mathrm{b}^{+} / \mathrm{CD} 11 \mathrm{c}^{-} / \mathrm{Ly}_{6 \mathrm{G}}{ }^{+}$) were increased in the combination group ( $\left.{ }^{*} P<0.05\right)$ compared with control or either treatment alone. (B) The percentage of classically and alternatively activated macrophages (defined as $\mathrm{CD} 11 \mathrm{~b}^{+} / \mathrm{F}_{480^{+}}$and $\mathrm{CD} 206^{-}$or $\mathrm{CD} 206^{+}$, respectively) is summarised. The DMXAA significantly increased the percentage of the classically activated 'M1' macrophages by approximately two-fold compared with vaccine alone ( ${ }^{\&} P<0.05$ between Combo and either control or Ad.E7) without changing the alternatively activated 'M2' macrophages. The left panel shows TC1/Ad.E7 model and the right panel shows LLC/Ad.IFN $\beta$ model. (C) Representative FACS tracings of F4/80 versus CD206 in macrophages in each group in the TC1/Ad.E7 model are shown. The numbers in each quadrant are the percentages of $\mathrm{M} 1\left(\mathrm{~F} 4 / 80^{+} / \mathrm{CD} 206^{-}\right)$and $\mathrm{M} 2\left(\mathrm{~F} 4 / 80^{+} / \mathrm{CD} 206^{+}\right)$macrophages. (D) The calculated 'immuno-stimulation ratio', that is, the ratio of non-M2 TAMs (antitumour) to M2 TAMs (protumour), is shown. The top panel shows TC1/Ad.E7 model and the bottom panel shows LLC/Ad.IFN $\beta$ model. Following combined treatment, this ratio increased markedly ( ${ }^{\star} P<0.05$ compared with all other treatments in both models).

DMXAA to Ad.E7 increased the percentage of E7-reactive CD8 ${ }^{+}$ cells by $50 \%$, but this did not reach statistical significance (data not shown).

The percentage of $\mathrm{CD}^{+}{ }^{+} \mathrm{T}$ cells from spleens harvested from mice 2 days after the boost Ad.E7 vaccine expressing the activation marker $4-1 \mathrm{BB}$ in mice treated with the combination of DMXAA and Ad.E7 was not increased compared with either treatment alone. Similar results were obtained using the activation marker CD25 (data not shown).

\section{DISCUSSION}

It is becoming increasingly apparent that in addition to the generation of CTLs, successful immunotherapy will require a second approach to decrease tumour-induced immune suppression, that is, 'inhibiting the inhibitors' (Pardoll and Drake, 2012). We and others have shown that blockade of formation or action of key immune inhibitory mediators such as prostaglandin E2 (using COX-2 inhibitors) (Jassar et al, 2005) or blocking TGF- $\beta$ (using kinase inhibitors or blocking antibodies) (Kim et al, 2008; Wallace et al, 2008; Llopiz et al, 2009) are effective in enhancing immunotherapy.

Given the importance of TAMs in producing and sustaining an inhibitory tumour microenvironment, these cells represent an attractive target for anticancer therapy. Even before the concept of immunosuppressive TAM was formally popularised, investigators used lipopolysaccharide (LPS) and LPS analogues to try to activate TAM (Klimp et al, 2002). Although effective in this regard, LPS was quite toxic with adverse systemic effects. The concept was next 
A

$\%$ Of $\mathrm{CD}^{+}$cells out of total tumour cells (TC1)

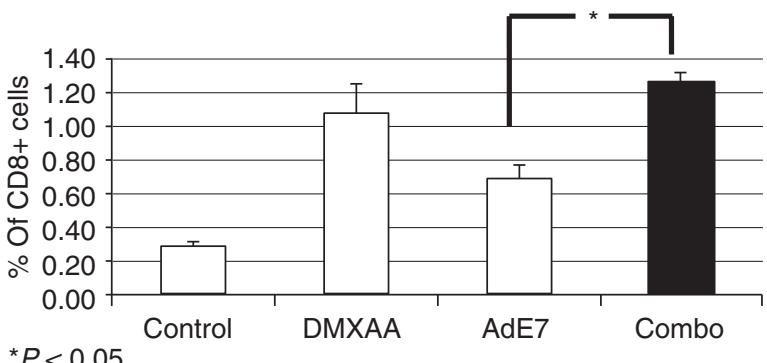

B

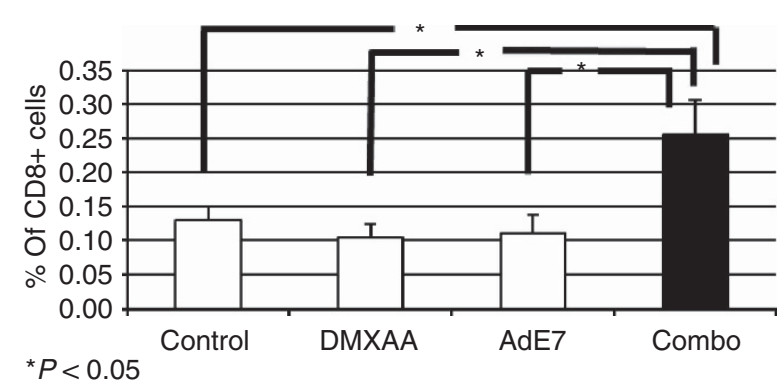

C
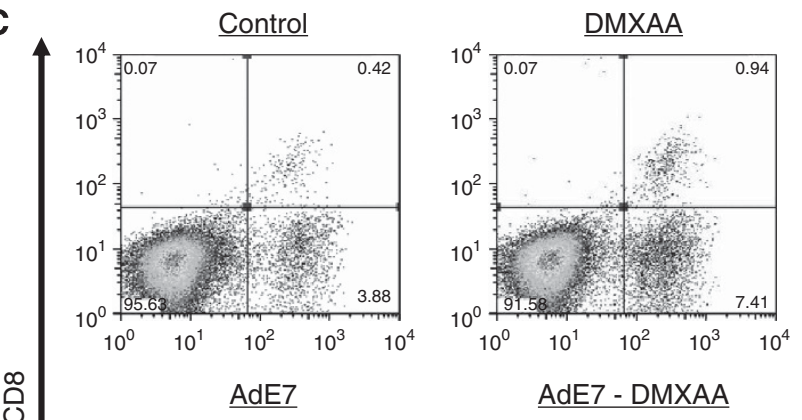

రి

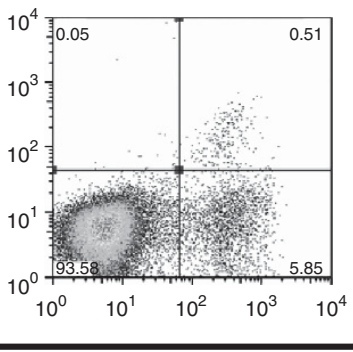

AdE7 - DMXAA

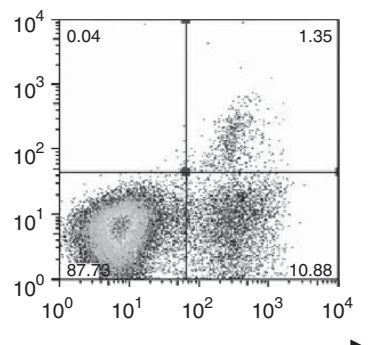

CD45

Figure 3. 5,6-Dimethylxanthenone-4-acetic-acid (DMXAA) in mice treated with immunotherapy increases the number of intratumoural $\mathrm{CD}^{+}{ }^{+}$T cells. Mice ( $n=4-6$ for each group) bearing large TC- 1 or LLC tumours were treated as in Figure 2. At 3 days after the injection of DMXAA, tumours were harvested. ( $\mathbf{A}$ and $\mathbf{B})$ The percentage of intratumoural $\mathrm{CD}^{+}$cells of total tumour by flow cytometry in the TC1/Ad.E7 model (A) and the LLC/Ad.IFN $\beta$ model (B). In both models, DMXAA combined with the vaccine more than doubled the percentage of intratumoural $\mathrm{CD} 8{ }^{+}$cells compared with vaccine alone $\left({ }^{\star} P<0.05\right)$. (C) Representative FACS tracings of $\mathrm{CD}_{4} 5^{+}$versus $\mathrm{CD} 8^{+}$cells in the TC1/Ad.E7 model are shown. The number in each upper-right quadrant is the percentage of $\mathrm{CD}^{+}$cells out of all tumour cells.

moved forward by using bacterial wall components with similar properties, but less toxicity, namely muramyl peptidoglycans (Kleinerman et al, 1992). More modern variations of this approach have used agents such as Toll-like receptor agonists (i.e., CPG oligonucleotides, imiquimod, CCL-34, and so on) (Meyer and
Stockfleth, 2008). In general, all these compounds have been hampered by toxicity or delivery issues.

Another approach that has been used to activate macrophages has been the use of cytokines such as interferon- $\gamma$, GM-CSF, and M-CSF (Klimp et al, 2002). None has yet been successful. The major problems with this approach have been the short half-life of these agents and the considerable systemic toxicity that they induce. Furthermore, the specificity of these approaches towards TAM is unclear. Finally, there has been recent interest in blocking the trafficking of monocytes into tumours, thus reducing the final number of TAMs. There is enthusiasm in using inhibitors of CCL2 (Fridlender et al, 2010) or the CSF-1/CSF-1 receptor axis (Aharinejad et al, 2004) from preclinical studies, and early clinical trials are beginning.

In contrast to the previously studied TAM activators, DMXAA is highly soluble, easily administered, well tolerated, and can potently activate TAMs in mouse tumour models (Ching et al, 1999; Jassar et al, 2005; Wang et al, 2009). We therefore used this compound as our 'proof-of-principal' macrophage-activating compound.

Using a variety of immunotherapy models, including classic vaccines and intratumoural cytokine delivery in multiple cell lines (Figure 1), we clearly show that combining immunotherapy with DMXAA increases antitumour efficacy compared with each treatment alone. This was most dramatically shown using an Ad.E7 vaccine directed against the HPV-E7 antigen expressed on TC1 cells (Figures 1A and 5). In this study, treatment of relatively large, established tumours with vaccine or DMXAA alone only resulted in a mild slowing of tumour growth. In contrast, combination treatment resulted in clear tumour regression and a number of cures. The combination of DMXAA with TC-1, as a model of HPV vaccination, has been recently evaluated (Peng et al, 2011; Zeng et al, 2011). Both these studies nicely showed that the combined treatment has a better clinical effect than either one of them alone. Our study in multiple models of immunotherapy supports these reports on the combined effect. In our work, we use DMXAA as a macrophage activator, focussing on this effect, which was not shown or discussed in these reports. As can be seen in Figure 5, depletion of macrophages largely decreased the effect of DMXAA on immunotherapy, suggesting, as we have previously shown (Jassar et al, 2005), that TAMs are a major component in this effect.

As DMXAA does not solely affect macrophages, we carried out a series of studies to study the phenotype of the TAM and CD8 T cells in order to confirm the mechanisms of this effect. We chose to study the time point that was 2 to 3 days after DMXAA administration as this was enough time for changes in the tumour microenvironment to occur, but the tumours were still similar in size to legitimise comparisons. As shown in Figure 2, and as we and others have reported, DMXAA (whether alone or in combination) did not cause a large change in TAM number, but did alter the phenotype of the TAMs away from the M2 phenotype, with increases in M1 or M0 type TAMs. This was evidenced by downregulation of the classic M2 TAM surface marker, the MMR2, or CD206 (Gallina et al, 2006; Roca et al, 2009), as well as changes in other known M1 and M2 markers (Supplementary Figure 1). The changes in cytokine mRNA (Table 1), which is the relative increase in the levels of M1 markers such as TNF $\alpha$, CCL5, and INF $\gamma$, are consistent with this. Again, similar to our previous work (Jassar et al, 2005), these changes were associated with increased numbers of tumour-infiltrating CD8 T cells (Figure 3), which were more activated (Figure 4 ) than in control tumours, especially in the LLCAd.IFN $\beta$ model. However, despite increased numbers of T cells, we postulate that one limitation of DMXAA in this context is that the antitumour activity of these $\mathrm{CD} 8^{+} \mathrm{T}$ cells in otherwise untreated animals is low and restricted, at least initially, to whatever endogenous antitumour response existed. The addition of immunotherapy, either intratumour or using specific tumour antigens, focusses the adaptive immune system towards the tumour. 
A \% Of $\mathrm{CD}^{+} 41 \mathrm{BB}^{+}$cells out of total tumour cells (TC1)

\% Of $\mathrm{CD}^{+} 41 \mathrm{BB}^{+}$cells out of total tumour cells (LLC)
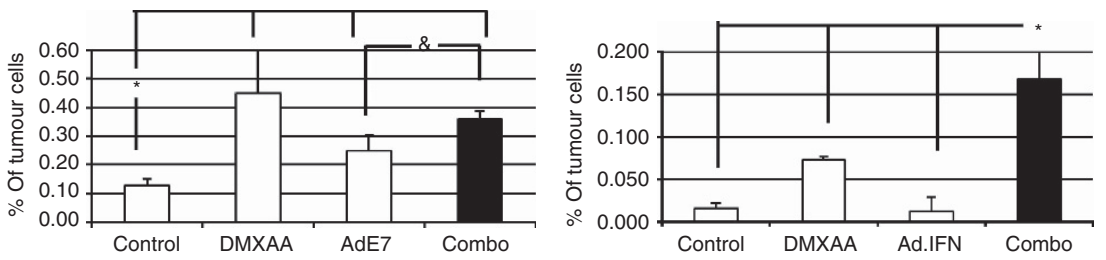

B \% Of CD8 ${ }^{+} \mathrm{CD} 25^{+}$cells out of total tumour cells (TC1) $\%$ Of CD8 $8^{+} \mathrm{CD} 25^{+}$cells out of total tumour cells (LLC)
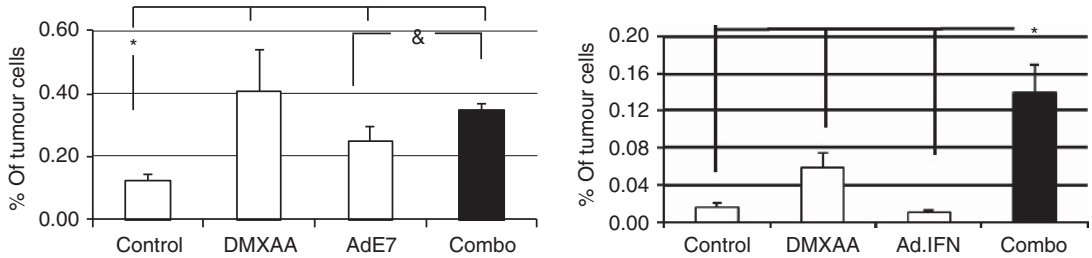

C $\%$ Of $\mathrm{CD} 8^{+} E 7^{+}$cells out of total tumours

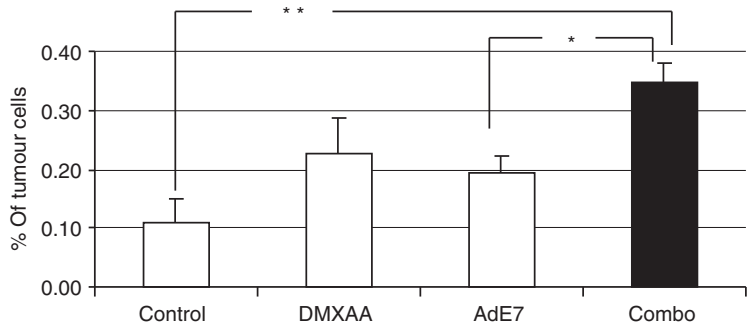

Figure 4. 5,6-Dimethylxanthenone-4-acetic-acid (DMXAA) in mice treated with immunotherapy increases the activity and specificity of intratumoural $\mathrm{CD}^{+}$T cells. Mice ( $n=4-6$ for each group) bearing large TC-1 or LLC tumours were treated as in Figure 2 . At 3 days after the injection of DMXAA, tumours were harvested. (A and $\mathbf{B}$ ) The percentage of activated intratumoural $\mathrm{CD} 8^{+} \mathrm{T}$ cells defined by expression of the activation markers 41BB (A) and CD25 (B). In the TC1/Ad.E7 model (A, left and B, left), CD8 ${ }^{+}$cell activation was increased in all treatment groups compared with control $\left({ }^{*} P<0.05\right)$. The percentage of activated $\mathrm{CD} 8^{+}$cells was increased in the combination treatment compared with Ad.E7 alone ( $\left.{ }^{\&} P=0.06\right)$. In the LLC/Ad.IFN $\beta$ model $\left(\mathbf{A}\right.$, right and $\mathbf{B}$, right), $C D 8^{+}$cell activation was increased in the combination group compared with all other treatments $\left({ }^{*} P<0.05\right)$. (C) The percentage of intratumoural E7-specific CD8 ${ }^{+}$cells $\left(\mathrm{Tet}^{+}\right)$. Combining DMXAA with Ad.E7 vaccine increased the percentage of tetramer-positive $\mathrm{CD}^{+}$cells by four-fold compared with control $(\star \star P<0.01)$ and two-fold compared with vaccine alone $\left({ }^{\star} P<0.05\right)$ and DMXAA alone $(P=0.057)$.

Also, as we have previously shown (Haas et al, 2006), and might be expected, the primary effect of the Ad.E7 vaccine is to generate antigen-specific CD8 T cells, particularly in the spleen. By itself, the vaccine results in only a small increase in the total number of CD8 $\mathrm{T}$ cells within the tumour (Figure $3 \mathrm{~A}$ ). Despite the ability to generate antitumour $\mathrm{T}$ cells systemically, a major limitation of the vaccine (as with most vaccines) is the suboptimal ability of the antigen-specific $\mathrm{T}$ cells to traffic into the tumour (Figures 3 and $4 \mathrm{C})$. It is interesting that even though the $\mathrm{T}$ cells face a somewhat 'hostile' environment, their presence does seem to result in a more immunostimulatory environment (Table 1).

Our mechanistic data show how the limitations of each approach can be complemented by the other: macrophage activation induces enhanced trafficking and reduced inactivation of the antigen-specific antitumour $\mathrm{T}$ cells induced by the vaccine. Thus, when compared with each therapy alone, combination therapy results in: (1) a more immunostimulatory tumour microenvironment (Figure 2 and Table 1) (2) more CD8 T cells within the tumours (Figure 3 ) and more antigen-specific $\mathrm{T}$ cells within the tumours (Figure 4).

Surprisingly, Matthews et al (2006) found that DMXAA did not synergize with adoptive transfer of $\mathrm{CD}^{+} \mathrm{T}$ cells. A possible explanation for that apparent contradiction to our findings lies in the described temporal actions of DMXAA in tumours (Baguley and Siemann, 2010). Specifically, if the vascular 'shut down' effects of DMXAA occur at the time of adoptive T-cell transfer, little increase in efficacy might be observed. The broader time window afforded by vaccine therapies may circumvent this potential timing problem.

There are some caveats to our study that should be considered. First, DMXAA is not a 'pure' macrophage activation agent but also has effects on other stromal components such as DCs (Wallace et al, 2007) and endothelial cells (Henare et al, 2012). It is possible that these other effects of DMXAA may have contributed to the combination effect. However, we believe that the TAM effect was highly important for two reasons: (1) we clearly show that the TAM phenotype was changed during therapy and (2) our macrophage depletion studies (using Clodronate liposomes) showed that loss of TAM significantly reduced the efficacy of combination therapy (Figure 5).

The second caveat relates to the observation that although DMXAA has highly potent stromal activation properties in mouse, in our hands (Fridlender et al, unpublished) and in other studies, it has much less activity in human cells (Wang et al, 2009; Henare et al, 2012). We believe that this is the reason that two recent clinical trials run by Novartis using DMXAA (Vadimezan) in combination with chemotherapy for lung cancer were recently halted for lack of efficacy (Lara et al, 2011). A number of groups are trying to develop analogues of DMXAA with similar human activity as is seen in mouse. Obviously, a better understanding of the way that DMXAA activates mouse leukocytes would be helpful in this regard. Although it has been established that DMXAA can activate macrophages through a number of key inflammatory pathways including the NF- $\kappa \mathrm{B}$ (Ching et al, 1999), type 1 


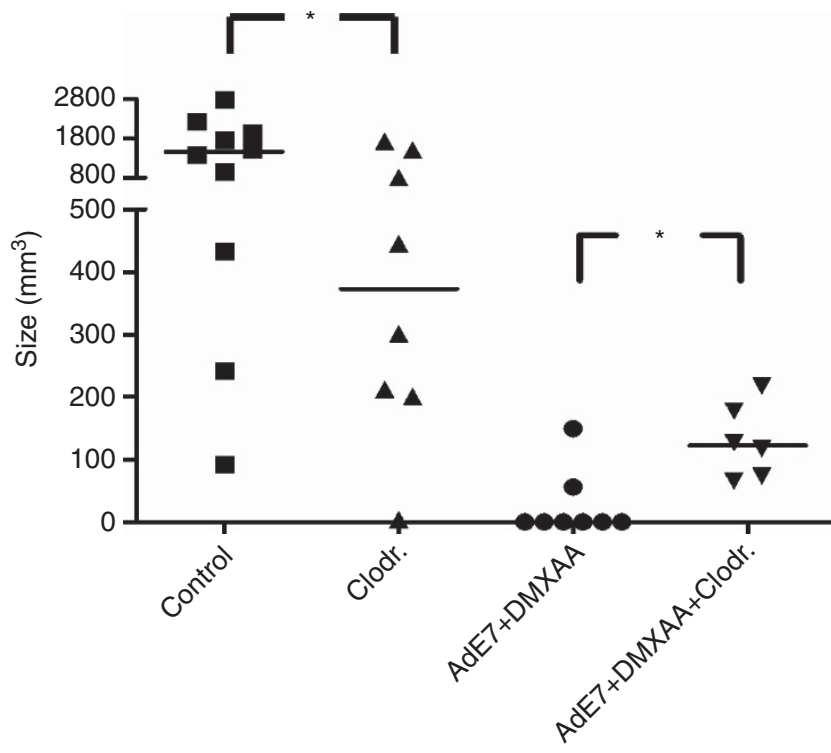

Figure 5. Depletion of macrophages reduces the effect of combining immunotherapy with DMXAA. Mice bearing large TC1 flank tumours were treated in one of the four ways: (1) 'empty' liposomes (control), (2) i.p. and intratumoural (i.t.) Clodronate liposomes (Clodr.),

(3) combination of Ad.E7 vaccine + DMXAA with empty liposomes (Ad.E7 + DMXAA), and (4) combination of Ad.E7 vaccine + DMXAA with Clodronate liposomes (Ad.E7 + DMXAA + Clodr.). Treatment with Clodronate liposomes reduced tumour size compared with mice treated with unloaded liposomes $\left({ }^{*} P=0.05\right)$. As previously shown, treatment with the combination of Ad.E7 and DMXAA markedly reduced tumour size, with 6 out of 8 cured. Addition of Clodronate liposomes inhibited the therapeutic efficacy of combination therapy $\left({ }^{\star} P<0.05\right)$. Each dot represents one mouse.

interferon (Roberts et al, 2007), NOD2 (Cheng et al, 2010), and MAP kinase (Sun et al, 2011) pathways, the DMXAA 'receptor' had not been identified. Excitingly, Prantner et al (2012) provided strong evidence that DMXAA binds to and specifically activates the 'stimulator of interferon gene' (STING). This finding opens up new possibilities for the identification of human homologues to DMXAA that might interact efficiently with human STING and thus succeed better in the treatment of human cancer. Our data suggest that if and when these analogues with enhanced human leukocyte-activating activity are identified, they could be highly useful immunotherapy-enhancing agents.

In summary, we demonstrated that modulating the phenotype of intratumoural macrophages dramatically augmented the effect of immunotherapy for NSCLC. Although it would not be advisable to use DMXAA (Vadimezan) in future human clinical trials, the principal of using tumour macrophage (stromal) activation (perhaps with an analogue with higher activity in human cells) or depletion in combination with immunotherapy holds great promise. As more effective approaches to develop antitumour $\mathrm{T}$ cells and to selectively alter the tumor microenvironment are developed, rapid combination of the two strategies should be encouraged in future immunotherapy trials.

\section{ACKNOWLEDGEMENTS}

This work was supported by a National Cancer Institution Grant PO1 CA 66726 (to SMA) and by The Legacy Heritage fund program of the Israel Science foundation (Grant No. 1574/09 to ZGF). The project described was also partially supported by a grant from the Israel Lung Association and by Grant number 1 P30
ES013508-02 from the National Institute of Environmental Health Sciences (NIEHS), NIH. Its contents are solely the responsibility of the authors and do not necessarily represent the official views of the NIEHS, NIH.

\section{REFERENCES}

Aharinejad S, Paulus P, Sioud M, Hofmann M, Zins K, Schafer R, Stanley ER, Abraham D (2004) Colony-stimulating factor-1 blockade by antisense oligonucleotides and small interfering RNAs suppresses growth of human mammary tumor xenografts in mice. Cancer Res 64: 5378-5384.

Baguley BC, Siemann DW (2010) Temporal aspects of the action of ASA404 (vadimezan; DMXAA). Expert Opin Investig Drugs 19: 1413-1425.

Biswas SK, Sica A, Lewis CE (2008) Plasticity of macrophage function during tumor progression: regulation by distinct molecular mechanisms. $J$ Immunol 180: 2011-2017.

Cheng G, Sun J, Fridlender ZG, Wang LC, Ching LM, Albelda SM (2010) Activation of the nucleotide oligomerization domain signaling pathway by the non-bacterially derived xanthone drug 5'6-dimethylxanthenone-4acetic acid (Vadimezan). J Biol Chem 285: 10553-10562.

Ching LM, Young HA, Eberly K, Yu CR (1999) Induction of STAT and NFkappaB activation by the antitumor agents 5,6-dimethylxanthenone-4acetic acid and flavone acetic acid in a murine macrophage cell line. Biochem Pharmacol 58: 1173-1181.

Dawicki W, Tania HW (2004) Expression and function of 4-1BB during CD4 versus CD8 T cell responses in vivo. Eur J Immunol 34: 743-751.

Finn OJ (2008) Cancer immunology. N Engl J Med 358: 2704-2715.

Fridlender ZG, Buchlis G, Kapoor V, Cheng G, Sun J, Singhal S, Crisanti C, Wang L-CS, Heitjan DF, Snyder LA, Albelda SM (2010) CCL2 blockade augments cancer immunotherapy. Cancer Res 70: 109-118.

Gabrilovich DI, Ostrand-Rosenberg S, Bronte V (2012) Coordinated regulation of myeloid cells by tumours. Nat Rev Immunol 12: 253-268.

Gallina G, Dolcetti L, Serafini P, De Santo C, Marigo I, Colombo MP, Basso G, Brombacher F, Borrello I, Zanovello P, Bicciato S, Bronte V (2006) Tumors induce a subset of inflammatory monocytes with immunosuppressive activity on CD8 + T cells. J Clin Invest 116: 2777-2790.

Haas AR, Sun J, Vachani A, Wallace AF, Silverberg M, Kapoor V, Albelda SM (2006) Cycloxygenase-2 inhibition augments the efficacy of a cancer vaccine. Clin Cancer Res 12: 214-222.

Henare K, Wang L, Wang LC, Thomsen L, Tijono S, Chen CJ, Winkler S, Dunbar PR, Print C, Ching LM (2012) Dissection of stromal and cancer cell-derived signals in melanoma xenografts before and after treatment with DMXAA. Br J Cancer 106: 1134-1147.

Hodi FS, O'Day SJ, McDermott DF, Weber RW, Sosman JA, Haanen JB, Gonzalez R, Robert C, Schadendorf D, Hassel JC, Akerley W, van den Eertwegh AJM, Lutzky J, Lorigan P, Vaubel JM, Linette GP, Hogg D, Ottensmeier CH, Lebbé C, Peschel C, Quirt I, Clark JI, Wolchok JD, Weber JS, Tian J, Yellin MJ, Nichol GM, Hoos A, Urba WJ (2010) Improved survival with Ipilimumab in patients with metastatic melanoma. $N$ Engl J Med 363: 711-723.

Jassar AS, Suzuki E, Kapoor V, Sun J, Silverberg MB, Cheung L, Burdick MD, Strieter RM, Ching LM, Kaiser LR, Albelda SM (2005) Activation of tumor-associated macrophages by the vascular disrupting agent 5,6dimethylxanthenone-4-acetic acid induces an effective CD8 + T-cellmediated antitumor immune response in murine models of lung cancer and mesothelioma. Cancer Res 65: 11752-11761.

Kantoff PW, Higano CS, Shore ND, Berger ER, Small EJ, Penson DF, Redfern $\mathrm{CH}$, Ferrari AC, Dreicer R, Sims RB, Xu Y, Frohlich MW, Schellhammer PF (2010) Sipuleucel-T immunotherapy for castration-resistant prostate cancer. $N$ Engl J Med 363: 411-422.

Killion JJ, Fidler IJ (1994) Systemic targeting of liposome-encapsulated immunomodulators to macrophages for treatment of cancer metastasis. Immunomethods 4: 273-279.

Kim S, Buchlis G, Fridlender ZG, Sun J, Kapoor V, Cheng G, Haas A, Cheung HK, Zhang X, Corbley M, Kaiser LR, Ling L, Albelda SM (2008) Systemic blockade of transforming growth factor-beta signaling augments the efficacy of immunogene therapy. Cancer Res 68: 10247-10256.

Kleinerman ES, Jia SF, Griffin J, Seibel NL, Benjamin RS, Jaffe N (1992) Phase II study of liposomal muramyl tripeptide in osteosarcoma: the cytokine cascade and monocyte activation following administration. J Clin Oncol 10: $1310-1316$. 
Klimp AH, de Vries EG, Scherphof GL, Daemen T (2002) A potential role of macrophage activation in the treatment of cancer. Crit Rev Oncol Hematol 44: 143-161.

Lara Jr PN, Douillard JY, Nakagawa K, von Pawel J, McKeage MJ, Albert I, Losonczy G, Reck M, Heo DS, Fan X, Fandi A, Scagliotti G (2011) Randomized phase III placebo-controlled trial of carboplatin and paclitaxel with or without the vascular disrupting agent vadimezan (ASA404) in advanced non-small-cell lung cancer. J Clin Oncol 29: 2965-2971.

Lin K-Y, Guarnieri FG, Staveley-O'Carroll KF, Levitsky HI, August JT, Pardoll DM, Wu T-C (1996) Treatment of established tumors with a novel vaccine that enhances major histocompatibility class II presentation of tumor antigen. Cancer Res 56: 21-26.

Llopiz D, Dotor J, Casares N, Bezunartea J, Diaz-Valdes N, Ruiz M, Aranda F, Berraondo P, Prieto J, Lasarte JJ, Borras-Cuesta F, Sarobe P (2009) Peptide inhibitors of transforming growth factor-beta enhance the efficacy of antitumor immunotherapy. Int J Cancer 125: 2614-2623.

Mantovani A, Germano G, Marchesi F, Locatelli M, Biswas SK (2011) Cancerpromoting tumor-associated macrophages: new vistas and open questions. Eur J Immunol 41: 2522-2525.

Matthews KE, Hermans IF, Roberts JM, Ching LM, Ronchese F (2006) 5,6-Dimethylxanthenone-4-acetic acid treatment of a non-immunogenic tumour does not synergize with active or passive CD8 + T-cell immunotherapy. Immunol Cell Biol 84: 383-389.

Meyer T, Stockfleth E (2008) Clinical investigations of Toll-like receptor agonists. Expert Opin Investig Drugs 17: 1051-1065.

Pardoll D, Drake C (2012) Immunotherapy earns its spot in the ranks of cancer therapy. J Exp Med 209: 201-209.

Peng S, Monie A, Pang X, Hung CF, Wu TC (2011) Vascular disrupting agent DMXAA enhances the antitumor effects generated by therapeutic HPV DNA vaccines. J Biomed Sci 18: 21.

Peng X, Hussain SF, Paterson Y (2004) The ability of two Listeria monocytogenes vaccines targeting human papillomavirus-16 E7 to induce an antitumor response correlates with myeloid dendritic cell function. J Immunol 172: 6030-6038.

Porter DL, Levine BL, Kalos M, Bagg A, June CH (2011) Chimeric antigen receptor-modified T cells in chronic lymphoid leukemia. $N$ Engl J Med 365: 725-733.

Prantner D, Perkins DJ, Lai W, Williams MS, Sharma S, Fitzgerald KA, Vogel SN (2012) 5,6-Dimethylxanthenone-4-acetic acid (DMXAA) activates stimulator of interferon gene (STING)-dependent innate immune pathways and is regulated by mitochondrial membrane potential. J Biol Chem 287: 39776-39788.

Roberts ZJ, Goutagny N, Perera PY, Kato H, Kumar H, Kawai T, Akira S, Savan R, van Echo D, Fitzgerald KA, Young HA, Ching LM, Vogel SN (2007) The chemotherapeutic agent DMXAA potently and specifically activates the TBK1-IRF-3 signaling axis. J Exp Med 204: 1559-1569.

Roca H, Varsos ZS, Sud S, Craig MJ, Ying C, Pienta KJ (2009) CCL2 and interleukin- 6 promote survival of human $\mathrm{CD} 11 \mathrm{~b}+$ peripheral blood mononuclear cells and induce M2-type macrophage polarization. J Biol Chem 284: 34342-34354.
Sica A, Larghi P, Mancino A, Rubino L, Porta C, Totaro MG, Rimoldi M, Biswas SK, Allavena P, Mantovani A (2008) Macrophage polarization in tumour progression. Semin Cancer Biol 18: 349-355.

Sica A, Rubino L, Mancino A, Larghi P, Porta C, Rimoldi M, Solinas G, Locati M, Allavena P, Mantovani A (2007) Targeting tumour-associated macrophages. Expert Opin Ther Targets 11: 1219-1229.

Sterman DH, Recio A, Haas AR, Vachani A, Katz SI, Gillespie CT, Cheng G, Sun J, Moon E, Pereira L, Wang X, Heitjan DF, Litzky L, June CH, Vonderheide RH, Carroll RG, Albelda SM (2010) A phase I trial of repeated intrapleural adenoviral-mediated interferon-beta gene transfer for mesothelioma and metastatic pleural effusions. Mol Ther 18: 852-860.

Sun J, Wang LC, Fridlender ZG, Kapoor V, Cheng G, Ching LM, Albelda SM (2011) Activation of mitogen-activated protein kinases by 5,6dimethylxanthenone-4-acetic acid (DMXAA) plays an important role in macrophage stimulation. Biochem Pharmacol 82: 1175-1185.

van Rooijen N, van Kesteren-Hendrikx E (2003) "In vivo" depletion of macrophages by liposome-mediated "suicide". Methods Enzymol 373: 3-16.

Wallace A, Kapoor V, Sun J, Mrass P, Weninger W, Heitjan DF, June C, Kaiser LR, Ling LE, Albelda SM (2008) Transforming growth factor-beta receptor blockade augments the effectiveness of adoptive T-cell therapy of established solid cancers. Clin Cancer Res 14: 3966-3974.

Wallace A, LaRosa DF, Kapoor V, Sun J, Cheng G, Jassar A, Blouin A, Ching LM, Albelda SM (2007) The vascular disrupting agent, DMXAA, directly activates dendritic cells through a MyD88-independent mechanism and generates antitumor cytotoxic T lymphocytes. Cancer Res 67: 7011-7019.

Wang LC, Thomsen L, Sutherland R, Reddy CB, Tijono SM, Chen CJ, Angel CE, Dunbar PR, Ching LM (2009) Neutrophil influx and chemokine production during the early phases of the antitumor response to the vascular disrupting agent DMXAA (ASA404). Neoplasia 11: 793-803.

Wilderman MJ, Sun J, Jassar AS, Kapoor V, Khan M, Vachani A, Suzuki E, Kinniry PA, Sterman DH, Kaiser LR, Albelda SM (2005) Intrapulmonary IFN-beta gene therapy using an adenoviral vector is highly effective in a murine orthotopic model of bronchogenic adenocarcinoma of the lung. Cancer Res 65: 8379-8387.

Zeng Q, Peng S, Monie A, Yang M, Pang X, Hung CF, Wu TC (2011) Control of cervicovaginal HPV-16 E7-expressing tumors by the combination of therapeutic HPV vaccination and vascular disrupting agents. Hum Gene Ther 22: 809-819.

Zwi LJ, Baguley BC, Gavin JB, Wilson WR (1990) Necrosis in non-tumour tissues caused by flavone acetic acid and 5,6-dimethyl xanthenone acetic acid. Br J Cancer 62: 932-934.

This work is published under the standard license to publish agreement. After 12 months the work will become freely available and the license terms will switch to a Creative Commons AttributionNonCommercial-Share Alike 3.0 Unported License.

Supplementary Information accompanies this paper on British Journal of Cancer website (http://www.nature.com/bjc) 